\title{
Transforming Entrepreneurial Resources to Competitive Advantage: The Role of Social Capital and Marketing capability
}

\author{
Aluisius Hery Pratono \\ Jatie K. Pudjibudojo
}

Universitas Surabaya, Raya Kalirungkut Surabaya 60293 Indonesia

Doi:10.5901/mjss.2016.v7n2s1p265

\begin{abstract}
Since small businesses are economic engines in many nations, the efforts to transform small business into competitive ones have come to a challenging issue. However, there is a gap in the entrepreneurship field, which is about limited and slow development of a cumulative body of knowledge, spring from lack of agreement on many key issues in entrepreneurship This study has intention to determine the impact of entrepreneurial orientation, social capital and entrepreneurial management of firm performance. To deal with complex relationship, the research framework involves mediating effect to refine theory. The structural equation model is tested with a survey on 390 respondents with SMEs context in Indonesia. The empirical result reveals that marketing capability has full mediating effect on relationship between firm performance and both entrepreneurial orientation and entrepreneurial management. Hence, the study indicates complementary mediating effect of marketing capability on the relation between social capital and firm performances. The contribution of this study confirms the resourcebased theory, which transformed into dynamic capability approach.
\end{abstract}

Keywords: firm performance, entrepreneurial orientation, entrepreneurial management, social capital, marketing capability

\section{Introduction}

In Indonesia, the small and medium enterprises (SMEs) are responsible for 99.9 percent of business units and $97.2 \%$ of domestic employment, but it just contributes to 57.9 percent of gross domestic product (Ministry of Cooperative and SMEs, 2013). The policy to promote SMEs (Small Medium Enterprises) is expected to promote economic growth and create job opportunities. Hence, the efforts to transform SMEs into competitive ones come to a challenging question about what determinant variables influence firm performance of SMEs in the long term. It appears that there is no single model that can comprehensively explain the best way how to achieve the firm performance.

Among the studies of contemporary entrepreneurship, entrepreneurial orientation (EO) has become considerable variable, which can foster the performance of SMEs. This concept explains a strategic posture in the long term through engaging in product innovation, undertaking risky ventures and proactive action for firm performance (Lumpkin, Cogliser, \& Schenider, 2009). However, there is a gap in the entrepreneurship field, which is about limited and slow development of a cumulative body of knowledge, spring from lack of agreement on many key issues in entrepreneurship (Raunch, Wiklund, Lumpkin, \& Frese, 2009).

Entrepreneurial management (EM) is believed as valuable resource in which business organizations run their business with opportunities-driven (Gürbüz \& Aykol, 2009). This approach enables the business organization to be more flexible in handling resources (Bradley, Wiklund, \& Shepherd, 2011). In addition, SMEs also consider their investment in social capital, which is believed to develop their organization culture and to enhance marketing capability.

This study aims to explain the relationship between firm performance and entrepreneurial variables, which includes entrepreneurial orientation, social capital and entrepreneurial management. To explain the complex relationship, the structural equation model involves marketing capability as mediating variable. This study responds the research gap about the need of mediating variable to identify the generative mechanism on how EO affects outcomes through mediating variables (Wales, Gupta, \& Mousa, 2013). There is also lack of EO analysis in rapidly developing economy (Slevin \& Terjesen, 2011). 


\section{Literature Review}

Literature review involves two sections, which are competitive advantage theory as underpinning theory and hypothesis development.

\subsection{Competitive advantage theory}

The concept of competitive advantage indicates firms with more value creating strategy than the competitor (Barney, 1991). This gains support from resource-based theory (RBT) that views transformation of valuable resource to greater organization goals becomes the most challenging issue, especially when there is lack of resource (Bradley, Wiklund, \& Shepherd, 2011). Firm performance refers to the theory of the firm that roots on neoclassical economics and states profit maximization as the reason why firms exist (Spullberg, 2009). Firms established with aim to serve human needs, then firm performance can be associated with how well firm fulfill the needs, which varied from numerous point of views, such as shareholders, employees, customers, or communities (Robert, 2008).

Performance measures to SMEs prove quite a challenge due to multidimensional constructs and no general definition of firm performance. The available literature regarding the effort of a firm to its performance is very extensive with a great number of different view points, such as firm growth, firm probability and various firm performances (Wales, Gupta, \& Mousa, 2013). In addition, the interests from various principles indicate many possible performance measures. For example, the sales performance, which is associated with reward for sales people refers to greater accountability in marketing management (Homburg, Artz, \& Wieseke, 2012). From the point of view of business owner, the measures of firm performance is useful to monitor the significant outcomes and behaviors of managements in order to improve performance (Garg, 2013). In addition, market-based measure is also different with accounting measure. Market-based measure refers to shareholder expectation about the future, while accounting measure reflect assessment from the previous period.

In entrepreneurial studies, both entrepreneurial orientation (EO) and entrepreneurial management (EM) have also emerged to explain the performance of SMEs (Sciascia, Mazzola, \& Chirico, 2012). Entrepreneurial orientation (EO) is associated with the way to run a business in the long term in which firms may be able to enhance business performance by adopting this concept. The theoretical and empirical inquiry of EO phenomenon has been emerging for over 30 years (Covin \& Wales, 2012). This is different from entrepreneurship, which is about how to set up a new business though both concepts lays emphasis on opportunity and resource effectiveness. Therefore, entrepreneurial management refers to entrepreneurial practices that firms conduct their management approach(Bradley, Wiklund, \& Shepherd, 2011). This concept assumes that management with entrepreneurial practices is driven by opportunity, flexible relationship, and target orientation (Gürbüz \& Aykol, 2009).

The main idea of social capital comes from social networks as valuable resources. The role of networks refers to status of the actors with cohesion and structural relationship as indicator measures. Social capital anchors on social network theory, which tries to predict behavior of social relationship in regards to assessing economic transaction (Jackson, 2008).

While social capital refers to be valuable resource, which can contribute to both private and public context, hence both negative and positive side effects or externalities need to be taken into account, including firm performance. For example, moral disengagement within networks can bring about negative work environment (Duffy, Scott, Shaw, Tepper, \& Aquino, 2012). In addition, the networks with external stakeholders come to challenges since market complexity becomes apparent. Under environmental turbulence, gap between marketing capability and market complexity becomes greater (Didonet, Simmon, Villacencio, \& Palmer, 2012).

In the context of SMEs, marketing capability is crucial to achieve its performance and to survival. This construct refers to source of competitive advantage in generates incomes (Morgan, Vorhies, \& Mason, 2009) with daily cash flow to recover their input cost. To narrow the gap between complexity and marketing capability requires continuous process to apply knowledge, skill and resource.

\subsection{Hypotheses development}

Hypothesis 1: Entrepreneurial orientation (EO) has direct effect on firm performance (FP).

It appears that EO plays pivotal role on firm performance. Since Miller and Friesen (1978) identify the construct of entrepreneurial orientation, a number of researches has showed the positive impact of EO on performance, such as positive impact of EO on growth of SMEs (Moreno \& Casillas, 2008), positive impact of EO on financial performance 
(Simon, Stachel, \& Covin, 2011), and relationship between radical EO and long-term competitive advantage (Bojica, Fuentes, \& Gómez-Gras, 2011). On the other hand, some empirical researches argue that entrepreneurial orientation has insignificant impact on firm performance. That significant impact occurs with business organizations that have less than 11 years experiences (Runyam, Droge, \& Swinney, 2008). The insignificant impact of EO on FP comes from lack of identification the relationship between risk and failure (Andersén, 2010).

Hypothesis 2: Social capital (SC) has direct effect on firm performance (FP).

The role of social capital on firm performance is dynamic at different phases within the organizational growth. Firms with high level of social capital may incur the costs of maintaining a set of relationships and ties to other firms that are deemed to be unprofitable (Alguezauri \& Filieri, 2013). However, at the earlier level of business cycles, there is negative relationship between social networks and firm performance (Pirolo \& Pesutti, 2010). Social networks in small business can lead to a gridlock, then followed by poor decision effectiveness (Jansen, Curseu, Vermeulen, Geurts, \& Gibeus, 2011).

Hypothesis 3: Entrepreneurial management (EM) has direct effect on firm performance (FP).

There are two references that consider entrepreneurial management as a single construct, i.e. Gürbuz and Aykol (2009) and Bradley, Wiklund, and Shepherd (2011). Both rely on four factors of entrepreneurial management, i.e. organizational culture, organizational structure, strategic orientation, and reward system with impact of firm performance. Entrepreneurial management has significant impact on firm performance, through elements of reward philosophy, entrepreneurial culture and growth orientation (Gürbüz \& Aykol, 2009), organization structure (Bradley, Wiklund, \& Shepherd, 2011). In addition, strategic orientation affected firm performance in positive direction (Morgan, Vorhies, \& Mason, 2009). Strategic orientation and structure organization have positive impact on firm performance regardless the size of the firms and business industry (Chatzoglou, Diamantidis, Vraimaki, \& Vranakis, 2011). The relationship between organization culture and firm performance is mixed.

Hypothesis 4: marketing capability (MC) mediates the relationship between entrepreneurial orientation (EO) and firm performance (FP)

Wales et al. (2013) highlight that future EO research should identify the generative mechanism on how EO affects FP through mediating variables. There is indirect effect in relationship between EO and FP (Baker \& Sinkula, 2009). Marketing capability can become a mediating variable to explain the relationship between EO and FP, which refers to product uniqueness as competitive advantage (Qureshi \& Kratzer, 2012).

Hypothesis 5: marketing capability (MC) mediates the relationship between social capital(SC) and firm performance (FP).

Social capital is necessary to achieve high level of firm performance, but not sufficient. The role of social capital to foster marketing capability and firm performance refers to the ambivalence dispute. This is called the paradox of networks, which means the resources provide access to valuable information but also generate problem when the firms try protect the information from their competitors. Marketing capability can be consider as mediator variable between structural social capital and marketing performance (Parra-Requina, Ruiz-Ortega, \& Garcia-Villaverde, 2011). Ahmadi et al. (2011) indicate that the link between social capital of the community and innovation performance of the SMEs doesn't seem to be straightforward on account of absorptive capacity.

Hypothesis 6: marketing capability (MC) mediates the relationship between entrepreneurial management $(E M)$ and firm performance (FP).

Considering that entrepreneurial management as latent variables, some factors were identified by the impact on market capability. Emphasizing organization culture on supplier's market culture and supplier's adhocracy culture that adhocracy and clans were described as inherently flexible and discretionary, organization culture significantly affects marketing capability (Lukas, Whitwell, \& Heide, 2013). As other element of entrepreneurial management, strategic orientation is also notified with significant impact on marketing capability (Griffith, Kieslling, \& Dabic (2012).

Table 1. The hypotheses

\begin{tabular}{ll}
\hline Hypotheses 1 & Significant relationship between EO and FP \\
Hypotheses 2 & Significant relationship between SC and FP \\
Hypotheses 3 & Significant relationship between EM and FP \\
Hypotheses 4 & MC mediates the relationship between EO and FP \\
Hypotheses 5 & MC mediates the relationship between SC and FP \\
Hypotheses 6 & MC mediates the relationship between EM and FP \\
\hline
\end{tabular}




\section{Research Method}

In order to answer the research questions and to test the hypothesis, this research uses quantitative approach with crosssection survey with a list of questionnaires by random sampling method. This approach allows the study to gain information to quantify relationship among the observed latent variables. This research employs a set of questionnaires that utilizes a standardized set.

The study gets sampling data frame of SMEs database published from the Government of Indonesia. Along with distributed questionnaires to randomized respondents, this study gains responds from 409 owner-managers of SMEs, who contributed to this study. The measures come from six latent variables in which each of variables constitutes from some items. The measures are adapted from some major literatures. Firm performance adapts from Aziz and Mahmood (2011), entrepreneurial orientation refers to Lumpkin et al. (2009), social capital refers to Bernades, 2010; Rouzies et al. (2010), Para-Requena et al. (2011), entrepreneurial management refers to Bradley et al. (2011), Gürbüz and Aykol (2009), and Lukas et al. (2013).

To deal with structural equation model, this study uses PLS (Partial Least Square), which estimates relationships through maximizing the variance with an iterative sequence of ordinary least square. This implies more relevant for application where strong assumption of multivariate normality can't be fully met. However, there are also some disadvantages, including no model fit measures and lack of classic inferential framework (Hair, Sarstedt, Ringle, \& Mena, 2012). The parameters are estimated by algorithm approach, while bootstrapping is used to test hypotheses (Henseler, 2010).

\section{Analysis}

The study uses explanatory factor analysis to summarize the structure of a set of variables, such as average variance extracted (AVE), composite reliability (CR) and Cronbach's alpha. AVE measures of all latent variables are greater than .50 , which means that variance due to construct is greater than the amount of variance due to measurement error. This indicates convergent validity of the observed variables are accepted. Hence, the CR of latent variables are greater than 0.8 and Cronbachs alpha are greater than 0.7. This indicates that the measures of observed variables are reliable or consistent (see Table 2).

Table 2: Quality criteria

\begin{tabular}{|c|c|c|c|c|c|}
\hline AVE & Composite Reliability & R Square & Cronbachs Alpha & Communality & Redundancy \\
\hline EM 0.528376 & 0.847453 & & 0.773063 & 0.528376 & \\
\hline EO 0.599791 & 0.856976 & & 0.778916 & 0.599791 & \\
\hline FP 0.654296 & 0.929702 & 0.549418 & 0.911687 & 0.654296 & 0.129499 \\
\hline MC 0.586007 & 0.848778 & 0.625313 & 0.764966 & 0.586007 & 0.176035 \\
\hline SC 0.718029 & 0.927144 & & 0.901752 & 0.718029 & \\
\hline
\end{tabular}

The cross-loading factors show correlation of the component scores of each latent variable with other items. A successful evaluation of discriminant validity shows that a test of a concept is not highly correlated with other tests designed to measure theoretically different concepts. This result provides evident that the measures of each item explains designation latent variable at greater value than 0.6 , which indicates high correlation of each items for its corresponding construct than other constructs, which implies that the variation of each item are great enough to explain the designated latent variable. Specifically, EO and SC have items with cross-loadings are greater than 0.8. Table 3 shows that loadings of the observed constructs are greater than for any of other constructs. The loading of each indicator is higher for its designated construct than for any of the other constructs, and each of the constructs loads highest with its own items, it can be inferred that the models' constructs differ sufficiently from one another. 
Table 3. Cross loading test

\begin{tabular}{lccccc}
\hline & EM & EO & FP & MC & SC \\
\hline EM03 & 0.759096 & & & & \\
EM05 & 0.615466 & & & & \\
EM08 & 0.742621 & & & & \\
EM09 & 0.810319 & & & & \\
EM20 & 0.691919 & & & & \\
E013 & & 0.796441 & & & \\
E019 & & 0.749260 & & \\
E021 & & 0.769959 & & & \\
E022 & & 0.781421 & & & \\
FP01 & & & 0.770150 & & \\
FP02 & & & 0.838901 & & \\
FP04 & & & 0.775447 & & \\
FP05 & & & 0.764364 & & \\
FP06 & & & 0.827011 & & \\
FP07 & & & 0.829995 & & \\
FP08 & & 0.851340 & 0.833521 & \\
MC01 & & & 0.644429 & \\
MC02 & & & & 0.798354 & \\
MC18 & & & & 0.772407 & \\
MC25 & & & & & 0.839537 \\
SC01 & & & & & 0.865178 \\
SC10 & & & & & \\
SC15 & & & & \\
SC18 & & & & \\
SC21 & & & & & \\
\hline
\end{tabular}

The bootstrapping output shows that not all independent variables have significant impact on firm performance. Specifically, both EO and EM have no direct impact on firm performance with t-test statistics of 1.189 and 1.503 respectively. This means that $\mathrm{H} 1$ and $\mathrm{H} 3$ are rejected. This result supports Kreiser and Davis (2010) that no direct impact of entrepreneurial orientation to firm performance. This result is also similar to Slater et al (2011) and Uzkurt et al (2013), which indicate that some elements of EM has no direct impact on firm performance dimension. The figure also shows $\mathrm{t}=$ 2.28, $p<.05$ with coefficient 2.65. Our finding suggests that $\mathrm{H} 2$ is accepted that means increasing social capital can increase firm performance directly. This result supports Bernades (2010), Wolz et al (2011), Alguezaui \& Filieri (2010) indicates a direct effect of SC on firm performance.

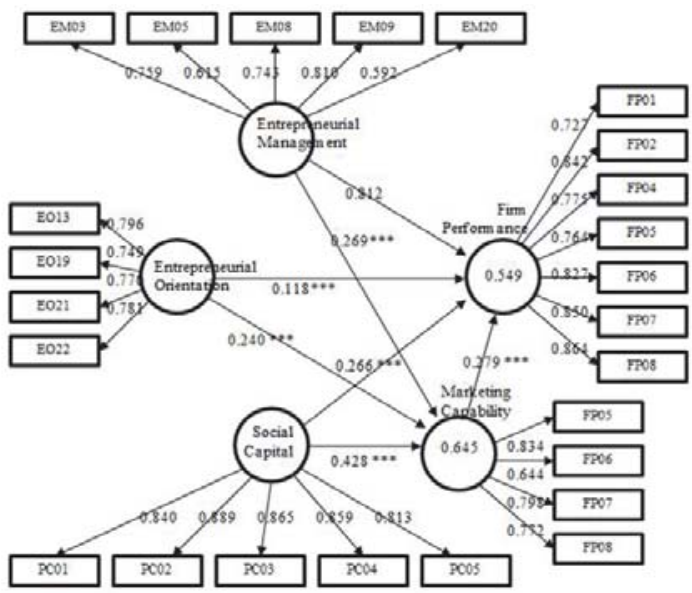

Figure 1. The estimated model 
Table 4 shows testing of overall model. In SEM (structural equation model), the test of marketing capability construct shows that the variable with highest impact on firm performance is social capital (weight 0.428), followed by entrepreneurial management (EM) and entrepreneurial orientation (EO), 0.269 and 0.239 respectively (see Table 3). Those three independent variables have a reasonable exploratory share with R2 of 0.625 (see Figure 2). The next step turns to the impact of EO, SC, EM, and MC on FP. Table 3 shows that MC provides the highest impact with weight of 0.404 , followed by MC with weight of 0.279 . The rest variables (EO and $E M)$ are considered with insignificant impact on FP.

Table 4. Total effect

\begin{tabular}{lcc}
\hline Latent variables & MC & FP \\
\hline Entrepreneurial Management (EM) & 0.269338 & 0.256778 \\
Entrepreneurial Orientation (EO) & 0.239775 & 0.185337 \\
Marketing Capability (MC) & & 0.279150 \\
Social Capital (SC) & 0.428237 & 0.404428 \\
\hline
\end{tabular}

Figure 1 shows reflective measurement model that factor loadings have greater values than 0.6 for all latent variables, such as EM and MC. SC has factor loading greater than 0.8 , while other variables (FP and EO) have greater values of factor loading than 0.7 . This indicates interrelations between all latent variables and their measurements are greater. This is consistent with quality criteria of latent variables (Table 2). In addition, the contribution of such independent variables $(E O, E M$, and $S C)$ on $M C$ refers to $R 2=0.625$. This indicates that 62,5 percent of variation of such independent variables explain variation of $\mathrm{MC}$, while R2 of FP shows that variation of independent variables and mediating variable explain 0.549 percent of variation of FP as dependent variable.

Figure 1 also shows that marketing capability provides mediating effects on the relation between firm performance and all independent variables: i.e. entrepreneurial orientation, entrepreneurial management, and social capital. All those variables have significant relationship with marketing capability with $t>2.32$ and $p<.01$. Therefore, marketing capability has significant impact on firm performance: $\mathrm{t}=4.51$ and $\mathrm{p}<.01$. This indicates that $\mathrm{H} 4, \mathrm{H} 5$, and $\mathrm{H} 6$ are accepted. Specifically, the measures of indirect effect of MC on the relationship between EO and FP is $0.240 \times 0.279=0.0669$, while the indirect effect of MC on the relationship between EM and FP is $0.269 \times 0.279=0.075$. Hence, when both indirect path and direct path have significant impact, then we can call MC has complementary mediating effect on the relationship between SC and FP (Zhao, Lynch, \& Chen, 2010). With bootstrap analysis, the result shows that mediating effect: $0.428 \times 0.279 \times 0.268=0.032$, which indicates as complementary mediating effect.

\section{Discussion}

Identifying mediating effect is typical approach to refine theory regarding process and understand a causal relationship (Rucker, Preacher, Tormala, \& Petty, 2011). This study provides evident that marketing capability (MC) has significant impact as mediating variable, which explain the relationship between firm performance (FP) and the three independent variables, EO, SC, and EM.

Specifically, MC is considered to provide full mediating effect to explain the relationship between EO and FP as well as EM and FP. This implies that the mechanism of both entrepreneurial concepts turns into firm performance needs $\mathrm{MC}$ as full mediating variable. Hence, MC has partial mediating effect on the relationship between SC and FP. It seems that terms of partial and full shows the effect size of MC as a mediating variable.

Full mediation effect tends to be indicated as the golden standard, which implies that the process on how EO and EM influence FP completely account on MC. Hence, partial mediation effect of MC on the relation between SC and FP might be considered as less important. In fact, there is wide range of indirect effect and the size of indirect effect can be identified. Future research could explore some unexplained direct paths.

In addition, the result of this study has some limitations, which needs to be extended in the future research. First, the sample frame is limited to SMEs located in the second big metropolitan area. Second is only one respondent to each firm who contribute to this research. Third, cross section data provides snap-shot observation. 


\section{Conclusion}

Apparently, the effort to transform small business into competitive ones should pay more attention on enhancing social capital. The main idea of social capital comes from social networks as valuable resources. The role of networks refers to status of the actors with cohesion and structural relationship as indicator measures. Social capital anchors on social network theory, which tries to predict behavior of social relationship in regards to assessing economic transaction (Jackson, 2008). While social capital refers to be valuable resource, which can contribute to both private and public context, hence both negative and positive side effects or externalities need to be taken into account, including firm performance. For example, moral disengagement within networks can bring about negative work environment (Duffy, Scott, Shaw, Tepper, \& Aquino, 2012). In addition, the networks with external stakeholders come to challenges since market complexity becomes apparent.

Secondly, the effort to transform valuable resources to small firm performance needs to focus on marketing capability. The result indicates that transforming such resources to marketing capability allows SMEs to achieve greater firm performance. This confirms the RBT that social capital, entrepreneurial orientation and entrepreneurial management can be considered as unique resources, which can foster SMEs to gain competitive advantage. The capability of SMEs to survive lies on their marketing capability, which should convert their valuable resources to daily cash flow to recover their cost of input. The management needs to embark on a series of marketing capability building program to strengthen collective skills with collaboration with internal and external stakeholders.

\section{References}

Aziz, S., \& Mahmood, R. (2011). The relationship between business model and performance of manufacturing small and medium enterprises in Malaysia . African Journal of Business Management , 5 (22), 8918-8932.

Alguezauri, S., \& Filieri, R. (2013). Investigating the role of social capital in innovation: sparse versus dense network. Journal of Knowledge Management , 14 (6), 891-909.

Andersén, J. (2010). A critical examination of the EO-performance relationship. International Journal of Entrepreneurial Behaviour \& Research , 16 (4), 309-328.

Baker, W., \& Sinkula, J. (2009). The complementary effects of market orientation and entrepreneurial orientation on profitability in small businesses . Journal of Small Business Management, 47 (4), 443-464.

Bojica, A., Fuentes, M., \& Gómez-Gras, J. (2011). Radical and incremental entrepreneurial orientation: the effect of knowledge acquisition. Journal of Management \& Organization , 17 (3), 326-343.

Bradley, S., Wiklund, J., \& Shepherd, D. (2011). Swinging a double-edged sword: The effect of slack on entrepreneurial management and growth. Journal of Business Venturing , 26 (5), 537-554.

Chatzoglou, P., Diamantidis, A., Vraimaki, E., \& Vranakis, S. (2011). Aligning IT, strategic orientation, and organizational structure . Business Process Management Journal , 17 (4), 663-687.

Covin, J., \& Wales, W. (2012). The measurement of entrepreneurial orientation. Entrepreneurship Theory and Practice, 36 (4), $677-702$.

Duffy, M., Scott, K., Shaw, J., Tepper, B., \& Aquino, K. (2012). A social context model of envy and social undermining. Academy of Management Journal , 55 (3), 643-666.

Didonet, S., Simmon, G., Villacencio, G., \& Palmer, M. (2012). The relationship between small business market orientation and environmental uncertainty . Marketing Intelligence \& Planning , 30 (7), 757-779.

Gürbüz, G., \& Aykol, S. (2009). Entrepreneurial management, entrepreneurial orientation and Turkish small firm growth. Management Research News, 32 (4), 321-336.

Garg, S. (2013). Venture boards: distinctive monitoring and implications for firm performance . Academy of Management Review , 38 (1), 90-108.

Hair, J., Sarstedt, M., Ringle, C., \& Mena, J. (2012). An assessment of the use of partial least squares structural equation modeling in marketing research. Journal of the Academic Marketing Science, 40, 414-433.

Henseler, J. (2010). On the convergence of the partial least squares path modeling algorithm . Computer Statistics, 25, $107-120$.

Homburg, C., Artz, M., \& Wieseke, J. (2012). Marketing performance measurement systems: does comprehensiveness really improve performance? . Journal of Marketing, 76 (3), 56-77.

Jackson, M. (2008). Social and Economic Networks. New Jersey, USA: Princeton University Press.

Jansen, R., Curseu, P., Vermeulen, P., Geurts, J., \& Gibeus, P. (2011). Social capital as a decision aid in strategic decision-making in service organizations. Management Decision , 49 (5), 737-747.

Lukas, B., Whitwell, G., \& Heide, J. (2013). Why do customers get more than they need? How organizational culture shapes product capacity decisions . Journal of Marketing , 77 (1), 1-12.

Lumpkin, G., Cogliser, C., \& Schenider, D. (2009). Understanding and measuring autonomy: an entrepreneurial orientation perspective. Entrepreneurship Theory and Practice , 33 (1), 47-69.

Moreno, A., \& Casillas, J. (2008). Entrepreneurial orientation and growth of SMEs: a causal model. Entrepreneurial Theory and Practice, 32 (3), 507-528. 
Morgan, N., Vorhies, D., \& Mason, C. (2009). Marketing orientation, marketing capabilities, and firm performance. Strategic Management Journal , 30, 909-920.

Qureshi, S., \& Kratzer, J. (2012). An investigation of antecedents and outcomes of marketing capabilities in entrepreneurial firms: an empirical study of small technology-based firms in Germany . Journal of Small Business and Entrepreneurship , 24 (1), 49-66.

Parra-Requina, G., Ruiz-Ortega, M., \& Garcia-Villaverde, P. (2011). Towards pioneering through capabilities in dense and cohesive social networks . Journal of Business \& Industrial Marketing , 27 (1), 41-56.

Pirolo, L., \& Pesutti, M. (2010). The impact of social capital on the start-ups' performance growth. Journal of Small Business Management, 48 (2), 197-227.

Sciascia, S., Mazzola, P., \& Chirico, F. (2012). Generation involvement in the top management team of family firms: exploring nonlinear effect on entrepreneurial orientation . Entrepreneurship Theory and Practice, , 37 (1), 69-85.

Simon, M., Stachel, C., \& Covin, J. (2011). The effect of entrepreneurial orientation and commitment to objective on performance . New England Journal of Entrepreneurship, 14 (2), 9-17.

Slevin, D., \& Terjesen, S. (2011). Entrepreneurial orientation: reviewing three papers and implication for further theoretical and methodological development. . Entrepreneurship Theory and Practice, 35 (9), 973-987.

Spullberg, D. (2009). The Theory of the Firm: microeconomics with Endogenous Entrepreneurs, Firm, Markets, and Organization. New York: Cambridge University Press.

Rucker, D., Preacher, K., Tormala, Z., \& Petty, R. (2011). Mediation analysis in social psychology: current practices and new recommendations. Social and Personal Psychology Compass , 5/6, 359-371.

Runyam, R., Droge, C., \& Swinney, J. (2008). Entrepreneurial orientation versus small business orientation: what are their relationships to firm performance? Journal of Small Business, 46 (4), 567-588.

Raunch, A., Wiklund, J., Lumpkin, G., \& Frese, M. (2009). Entrepreneurial orientation and business performance: an assessment of past research and suggestion for the future . Entrepreneurship Theory and Practice, 33 (3), 761-787.

Robert, J. (2008). The modern firm: organizational design for performance and growth. New York: Oxford University Press.

UMKM, M. K. (2013). Annual Accountability Report. Jakarta: Indonesia Ministry of Cooperation and SMEs.

Wales, W., Gupta, V., \& Mousa, F. (2013). Empirical research on entrepreneurial orientation: An assessment and suggestions for future research. nternational Small Business Journal , 31 (4), 357-383.

Zhao, X., Lynch, J., \& Chen, Q. (2010). Reconsidering Baron and Kenny: myths and truths about mediation analysis. The Journal of Consumer Research, 37 (2), 197-206. 